\title{
Publisher Correction: Coherent interaction of atoms with a beam of light confined in a light cage
}

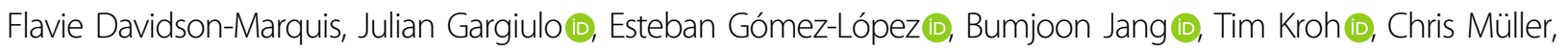
Mario Ziegler, Stefan A. Maier, Harald Kübler (1), Markus A. Schmidt (1) and Oliver Benson

Correction to: Light: Science \& Applications

https://doi.org/10.1038/s41377-021-00556-z

published online 31 May 2021

After publication of this article ${ }^{1}$, it is noticed the article contained an error.

In Table 1, the data in the line 'Length ( $\mathrm{mm})$ ' is missing. The complete Table 1 is provided in this correction.

The original article has been updated.
Published online: 01 July 2021

\section{References}

1. Davidson-Marquis, F. et al. Coherent interaction of atoms with a beam of light confined in a light cage. Light Sci. Appl. 10, 114 (2021). 
Table 1 Comparative overview on light delay in different types of waveguides

\begin{tabular}{|c|c|c|c|c|c|c|}
\hline & F. sp. & LC & HC PCF 29 & Rectang. ARROW 52 & $\mathrm{HC} \mathrm{PCF}^{20}$ & Improv. LC \\
\hline$\widetilde{\mathrm{I}}_{\text {str }} / \widetilde{\mathrm{I}}_{\text {(f.sp) }}$ & 1 & 4.4 & - & - & - & 75 \\
\hline maximum & 1 & 19 & - & 130 & 175 & 84 \\
\hline Length (mm) & 5 & 4.5 & 200 & 4 & 200 & 19.5 \\
\hline Delay to (ns) & 3.9 & 3.1 & - & 16 & 12.5 & 29 \\
\hline Frac. delay F & 0.055 & 0.063 & - & 0.2 & 30 & $0.89+$ \\
\hline Fill time (days) & $\sim 1$ & $\sim 1$ & $\sim 10^{4}$ & - & $\sim 10^{4}$ & $\sim 1$ \\
\hline Chip-integrable & No & Yes & No & Yes & No & Yes \\
\hline LIAD required & No & No & Yes & No & Yes & No \\
\hline$Q_{\text {atom }}\left(10^{10} \mathrm{~cm}^{-3}\right)$ & 10 & 7 & 76 & 120 & 5 & $\sim 7^{*}$ \\
\hline
\end{tabular}

